\title{
Erratum
}

\section{Erratum to "Variation of the Lateral Sacral Artery in relation to Sciatic Neuropathy"}

\author{
Waseem Al Talalwah, ${ }^{1}$ Shorok Ali Al Dorazi, ${ }^{2}$ and Roger Soames ${ }^{3}$ \\ ${ }^{1}$ Department of Basic Medical Sciences, College of Medicine, King Saud bin Abdulaziz University for Health Sciences, \\ P.O. Box 3660, Riyadh 11481, Saudi Arabia \\ ${ }^{2}$ Directorate of Prevention and Control of Healthcare Associated Infection, Eastern Province, MOH, P.O. Box 411, \\ Saihat 31972, Saudi Arabia \\ ${ }^{3}$ Centre for Anatomy and Human Identification, College of Art, Science and Engineering, University of Dundee, \\ Dundee DD1 5EH, UK \\ Correspondence should be addressed to Waseem Al Talalwah; altalalwahw@ksau-hs.edu.sa
}

Received 4 December 2014; Accepted 8 December 2014; Published 21 December 2014

Copyright (C) 2014 Waseem Al Talalwah et al. This is an open access article distributed under the Creative Commons Attribution License, which permits unrestricted use, distribution, and reproduction in any medium, provided the original work is properly cited.

In the abstract "The current study of 342 specimens from 171 cadavers (79 male, 92 female)" is corrected as "The current study of 342 specimens from 171 cadavers (92 male, 79 female)."

As a result "the lateral sacral artery is congenital absence in $0.3 \%$." is corrected as "lateral sacral artery is congenital absence in $0.4 \%$."

Tables 1 and 2 of the published paper are corrected as the following tables. 
TABLE 1: Origin of the lateral sacral artery.

\begin{tabular}{|c|c|}
\hline Origin & Incidence $^{1}$ \\
\hline Anterior trunk of the internal iliac artery & $1.0 \%$ \\
\hline Dorsomedial aspect of the internal iliac artery & $3.7 \%$ \\
\hline Posterior trunk of the internal iliac artery & $79.1 \%$ \\
\hline Superior gluteal artery & $16.8 \%$ \\
\hline Inferior gluteal artery & $5.4 \%$ \\
\hline Internal pudendal artery & $0.3 \%$ \\
\hline Persistent sciatic artery & $8.8 \%$ \\
\hline Congenital absence & $0.4 \%$ \\
\hline
\end{tabular}

TABLE 2: The incidence of the lateral sacral arteries number observed in series studies and current study.

\begin{tabular}{lcccccc}
\hline Number\study & Tonkoff [10] & Naguib et al. [12] & Sadler [13] & Sharpey et al. [14] & Poynter [15] & Current study \\
\hline Single & $0 \%$ & $30 \%$ & $55 \%$ & $26 \%$ & $50 \%$ & $77.2 \%$ \\
Double & $98 \%$ & $48 \%$ & $45 \%$ & $61.5 \%$ & $42.5 \%$ & $7.5 \%$ \\
Triple & $2 \%$ & $9 \%$ & $0 \%$ & $11 \%$ & $2.3 \%$ \\
Quadruple & $0 \%$ & & $0 \%$ & $1.5 \%$ & $0.3 \%$ \\
\hline
\end{tabular}

The lateral sacral artery commonly arose from the internal iliac artery in different numbers but was found to be absent in one specimen (0.4\%). Observations based on 342 specimens ( 45 specimens have been excluded due to missing data). 

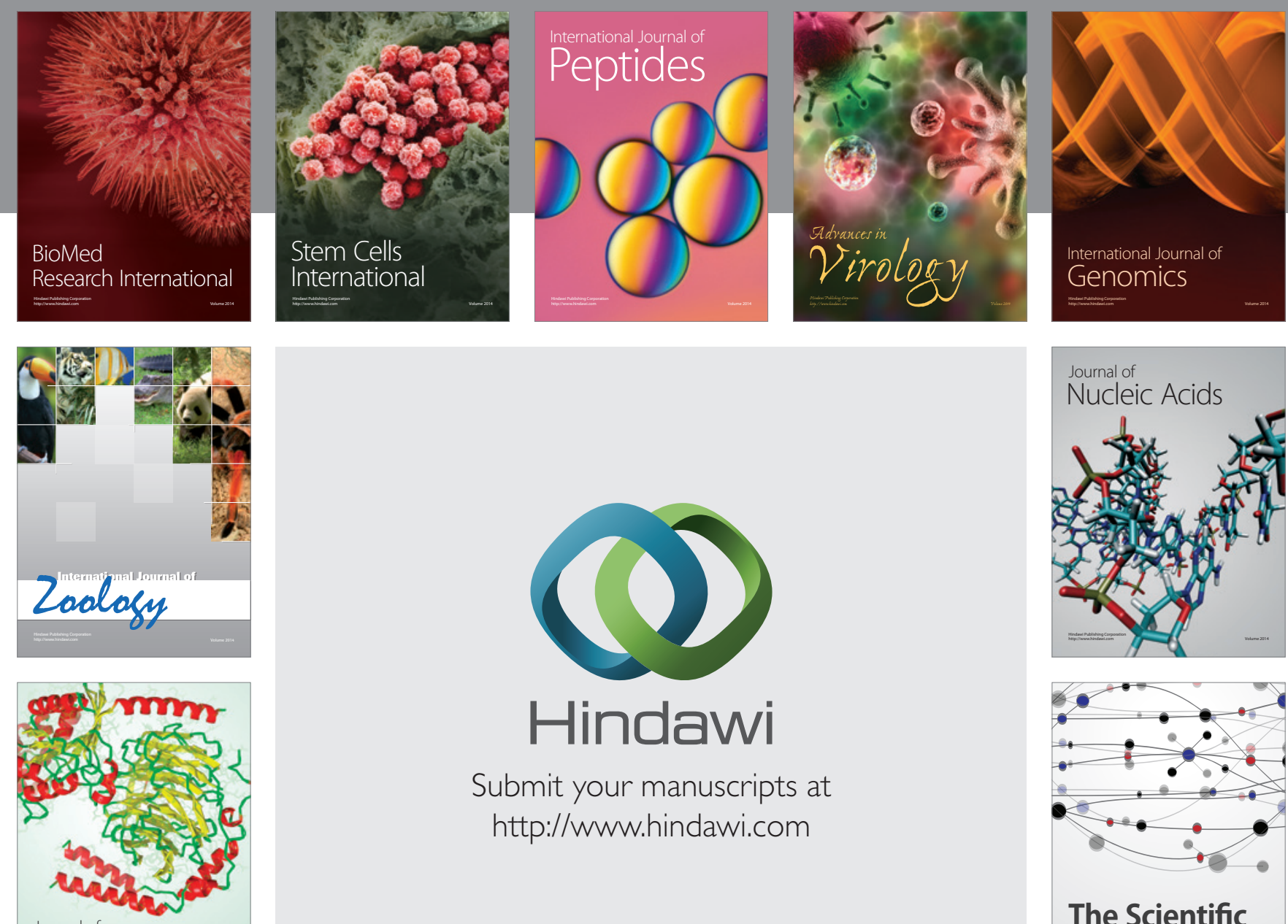

Submit your manuscripts at

http://www.hindawi.com

Journal of
Signal Transduction
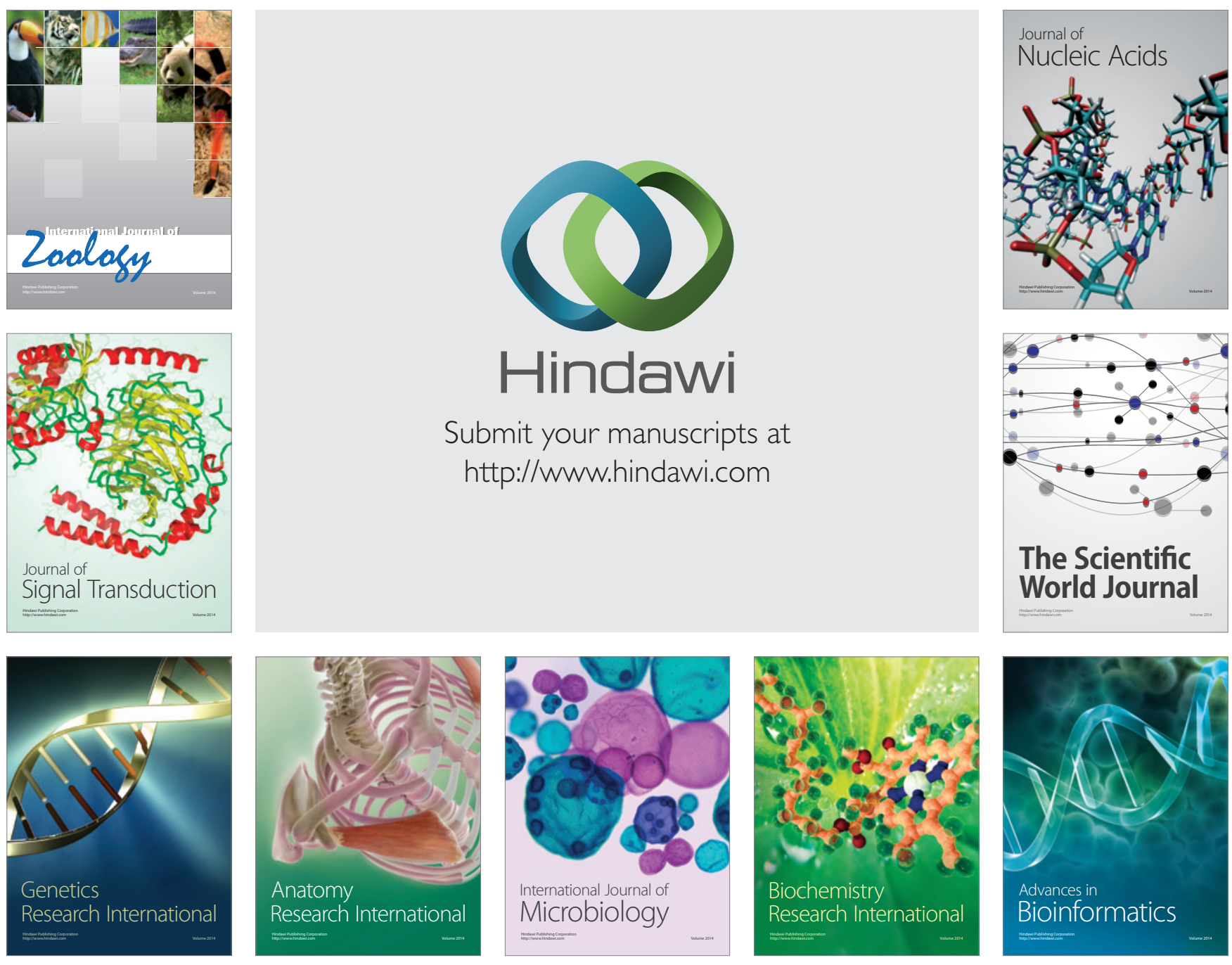

The Scientific World Journal
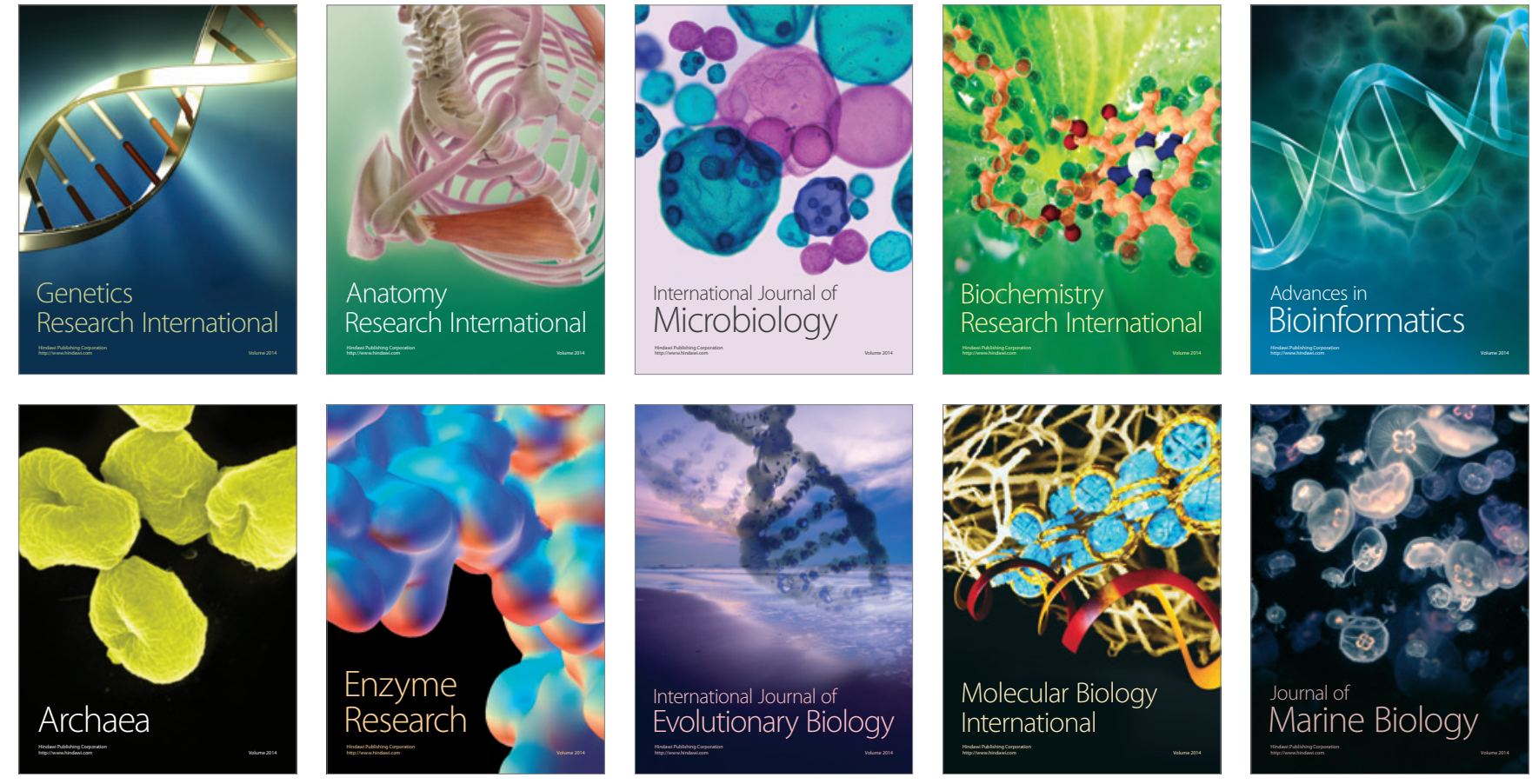